\title{
Inhibitory Properties of Aqueous Ethanol Extracts of Propolis on Alpha-Glucosidase
}

\author{
Hongcheng Zhang, ${ }^{1,2}$ Guangxin Wang, ${ }^{1}$ Trust Beta, ${ }^{3}$ and Jie Dong ${ }^{1,2}$ \\ ${ }^{1}$ Bee Research Institute, Chinese Academy of Agricultural Sciences, Beijing 100093, China \\ ${ }^{2}$ National Research Center of Bee Product Processing, Ministry of Agriculture, Beijing 100093, China \\ ${ }^{3}$ Department of Food Science, University of Manitoba, Winnipeg, MB, Canada R3T 2N2 \\ Correspondence should be addressed to Jie Dong; jiedon@126.com
}

Received 4 September 2014; Revised 15 December 2014; Accepted 18 December 2014

Academic Editor: Flávia R. F. do Nascimento

Copyright (C) 2015 Hongcheng Zhang et al. This is an open access article distributed under the Creative Commons Attribution License, which permits unrestricted use, distribution, and reproduction in any medium, provided the original work is properly cited.

\begin{abstract}
The objective of the present study was to evaluate the inhibitory properties of various extracts of propolis on alpha-glucosidase from baker's yeast and mammalian intestine. Inhibitory activities of aqueous ethanol extracts of propolis were determined by using 4-nitrophenyl-D-glucopyranoside, sucrose and maltose as substrates, and acarbose as a positive reference. All extracts were significantly effective in inhibiting $\alpha$-glucosidase from baker's yeast and rat intestinal sucrase in comparison with acarbose $(P<$ 0.05 ). The $75 \%$ ethanol extracts of propolis (75\% EEP) showed the highest inhibitory effect on $\alpha$-glucosidase and sucrase and were a noncompetitive inhibition mode. 50\% EEP, 95\%, EEP and 100\% EEP exhibited a mixed inhibition mode, while water extracts of propolis (WEP) and 25\% EEP demonstrated a competitive inhibition mode. Furthermore, WEP presented the highest inhibitory activity against maltase. These results suggest that aqueous ethanol extracts of propolis may be used as nutraceuticals for the regulation of postprandial hyperglycemia.
\end{abstract}

\section{Introduction}

Diabetes mellitus is the most common endocrine disorder disease caused by inherited or acquired deficiency in insulin excretion and by decreased responsiveness of the organs to secreted insulin. According to the recent reports, the number of diabetic patients in the world would amount to 366 million in 2030 and death related to diabetes mellitus accounts for about $9 \%$ global mortality, particularly type 2 diabetes mellitus [1]. In China, more than 92 million adults have diabetes, and 95 percent of them are type 2 diabetes mellitus, according to the survey of current epidemiology [2]. Because of more-affluent lifestyles, the number of people with diabetes is predicted to increase in the future. Patients with type 2 diabetes mellitus usually tend to have long-term complications, such as retinopathy, cataract, atherosclerosis, neuropathy, nephropathy, and impaired wound healing [3]. Diabetes mellitus is characterized by abnormally high plasma glucose. Hyperglycemia has played a central role in pathogenesis of complications related to diabetes mellitus. In treatment of type 2 diabetes, suppression of postprandial hyperglycemia can decrease the risk of those complications. Hence, control of postprandial hyperglycemia should be a primary goal in the prevention and management of type 2 diabetes.

Alpha-glucosidases are a series of enzymes, including sucrase and maltase, located in the brush-border surface of intestinal cell, which catalyze the final step in the digestive process of carbohydrates to release absorbable monosaccharides resulting in increased blood glucose levels [4]. If $\alpha$ glucosidases are inhibited, the liberation of $\mathrm{D}$-glucose from dietary complex carbohydrates can be retarded. Thus, $\alpha$ glucosidase inhibitors have become candidates of hot pursuits to delay the digestion and absorption of carbohydrates and restrain postprandial hyperglycemic excursions. Alphaglucosidase inhibitors as one of therapeutic approaches for diabetes mellitus have been known since the early 1990s [5]. At present, some $\alpha$-glucosidase inhibitors, such as acarbose, miglitol, and voglibose, have been approved for clinical use in the management of type 2 diabetes, as well as the treatment of obesity. However, some synthetic $\alpha$-glucosidase inhibitors 
have side-effects, such as flatulence, diarrhea, and abdominal cramping, all of which are associated with incomplete carbohydrate absorption [6]. As a result, many researchers have focused on novel $\alpha$-glucosidase inhibitors from natural materials, which are used to develop functional foods or lead compounds for antidiabetic treatment including Syagrus romanzoffiana, Adhatoda vasica Nees, and Syzygium cumini (Linn.) seed kernel [7-9]. Some medicinal plant species have more potent $\alpha$-glucosidase inhibitory activities than powerful synthetic $\alpha$-glucosidase inhibitors such as acarbose [10].

Propolis is a colored and aromatic colloidal substance collected by honeybees through adding their saliva secreted to the resinous plant exudate, which is used to build honeycomb and to fight against the invasion of pathogenic microorganism. The chemical composition of propolis varies and depends mainly upon the local flora in the region of collection. At present, more than 300 components have been identified including flavonoids, phenolic acids, alcohols and their esters, ketones, and inorganic compounds [11]. Propolis has been applied in popular folk medicine since $3000 \mathrm{BC}$ due to possessing a broad spectrum of biological activities such as antioxidant, antimicrobial, anti-inflammatory, antiviral, anticancer, and antihepatotoxic properties [12]. Recent studies show that ethanol and water extracts of propolis can control the glycemia and modulate glucose and lipid metabolism in STZ-induced diabetic rats $[13,14]$. Ethanolic extracts of Brazilian green propolis were also shown to possess therapeutic potential in STZ-induced diabetic rats [15]. In China, propolis has been approved for use in functional foods carrying a health claim of controlling glycemia in 1999 by the Ministry of Health [16]. Moreover, propolis has been accepted as adjuvant therapy drugs for diabetes mellitus in Chinese Pharmacopoeia in 2005 [17]. However, there are few reports whether controlling glycemia of propolis is related to its inhibitory activities against $\alpha$-glucosidase.

In the present study, we assessed inhibitory effects of aqueous ethanol extracts of propolis on alpha-glucosidase and the kinetics of enzyme inhibition by using the MichaelisMenten model.

\section{Material and Methods}

2.1. Chemicals and Reagents. Alpha-glucosidases (EC 3.2.1.20) from baker's yeast, rat intestinal acetone powder, p-nitrophenyl- $\alpha$-D-glucopyranoside (PNP-glucoside), sucrose, maltose, piperazine-1,4-bisethanesulfonic acid (PIPES), FolinCiocalteu, and Glucose-Trinder 100 were obtained from Sigma Chemical Co. (St. Louis, MO, USA). Dimethyl sulphoxide (DMSO, cell culture grade) was purchased from Applichem Co. (Darmstadt, Germany). The crude propolis was procured from Bee Research Institute, Chinese Academy of Agricultural Science (Beijing, China). All reagents were of analytical grade.

2.2. Preparation of Aqueous Ethanol Extracts of Propolis. Propolis extracts were prepared as described by Huang et al. [18] with slight modification. Crude propolis (10 grams) was, respectively, extracted with $200 \mathrm{~mL}$ aqueous ethanol solvent at concentrations ranging from $0 \%, 25 \%, 50 \%, 75 \%$, and $95 \%$ to $100 \%$ (in water, v/v) by using ultrasonic extract for 4 hours (ultrasonic extractor, DCTZ-1000, Beijing Hongxianglong Biotechnol Co. Ltd., Beijing, China). The suspensions were centrifuged at $12,000 \times \mathrm{g}$ for $30 \mathrm{~min}$ to obtain supernatants which were concentrated at $45^{\circ} \mathrm{C}$ in a rotary evaporator (Rotavapor, R-215, Buchi Co., Ltd., Switzerland) and then freeze-dried. Extracts were stored in zip lock bag at $4^{\circ} \mathrm{C}$ in darkness. The extracts were dissolved by DMSO until application.

2.3. Determination of Total Phenolic Contents. Total polyphenol contents in propolis extracts were determined according to the Folin-Ciocalteu colorimetric method with slight modifications [19]. A standard curve was built with gallic acid solution. Aliquots ranging from 0 to $1.2 \mathrm{~mL}$ of standard solution $(100 \mu \mathrm{g} / \mathrm{mL})$ were pipetted into $10 \mathrm{~mL}$ volumetric flasks containing $6 \mathrm{~mL}$ distilled water. $0.5 \mathrm{~mL}$ of $2 \mathrm{~mol} / \mathrm{L}$ Folin-Ciocalteu solution and $1.5 \mathrm{~mL}$ of $10 \% \mathrm{Na}_{2} \mathrm{CO}_{3}(\mathrm{w} / \mathrm{v})$ were added and the volume made up to $10 \mathrm{~mL}$ with distilled water. Following mixing, the solution was measured at $765 \mathrm{~nm}$ after $10 \mathrm{~min}$ by using UV-2500/Ultraviolet visible spectrophotometer with UVProbe software (Shimadzu Co., Ltd., Tokyo, Japan). The blank was also prepared without addition of the standard aliquots. For determination of the total phenolic contents in propolis extracts, $20 \mu \mathrm{L}$ of aqueous solution at a concentration of $1 \mathrm{mg} / \mathrm{mL}$ was used. Total phenolic contents were expressed as milligrams gallic acid equivalents per gram extract (mg GAE/g).

2.4. Determination of Total Flavonoid Contents. Contents of flavonoid in propolis extracts were determined according to the method of Kaijv et al. [20], with minor modifications. A standard curve was built with chrysin solution. Aliquots ranging from 0 to $12 \mathrm{~mL}$ of standard solution $(100 \mu \mathrm{g} / \mathrm{mL})$ were pipetted into $25 \mathrm{~mL}$ volumetric flasks containing $1.0 \mathrm{~mL}$ aliquots of $5 \% \mathrm{NaNO}_{2}(\mathrm{w} / \mathrm{v})$ solution. After $6 \mathrm{~min}, 1.0 \mathrm{~mL}$ $10 \% \mathrm{AL}\left(\mathrm{NO}_{3}\right)_{3}(\mathrm{w} / \mathrm{v})$ solution was added and thoroughly mixed. $10 \mathrm{~mL} 4.3 \% \mathrm{NaOH}(\mathrm{w} / \mathrm{v})$ solution was added after $6 \mathrm{~min}$ and the volume was made up with ethanol. The blank was prepared by using ethanol instead of standard solution or sample solutions. After $15 \mathrm{~min}$, the absorbance was measured at $510 \mathrm{~nm}$ by using UV-2500/Ultraviolet visible spectrophotometer with UVProbe software (Shimadzu Co., Ltd., Tokyo, Japan). For determination of the total flavonoid contents in propolis extracts, $0.5 \mathrm{~mL}$ of aqueous solution at a concentration of $1 \mathrm{mg} / \mathrm{mL}$ was used. Total flavonoid contents were expressed as milligrams chrysin equivalents per gram extract (CE).

2.5. Inhibitory Activity Assay for Baker's Yeast Alpha-Glucosidase. Alpha-glucosidase inhibitory effect of propolis extracts was assayed according to the procedure described previously by Kim et al. [21] with slight modifications. The enzyme reaction was performed using PNP-glycoside as a substrate in $0.1 \mathrm{M}$ PIPES buffer ( $\mathrm{pH}$ 6.8). $1 \mathrm{~mL}$ PNP-glycoside $(1.0 \mathrm{mM})$ was premixed with $0.1 \mathrm{~mL}$ propolis extracts at various concentrations $(2 \mu \mathrm{g} / \mathrm{mL}-200 \mu \mathrm{g} / \mathrm{mL})$ in $2.05 \mathrm{~mL}$ PIPES buffer and the reaction system was preheated at $37^{\circ} \mathrm{C}$ for $30 \mathrm{~min}$. Then, $0.5 \mathrm{~mL}$ enzyme solution $(0.11 \mathrm{U} / \mathrm{mL})$ was added into mixture and 
absorbances were immediately measured at 30-second intervals for $15 \mathrm{~min}$ at $415 \mathrm{~nm}$ using UV-2500/Ultraviolet visible spectrophotometer with UVProbe software (Shimadzu Co., Ltd., Tokyo, Japan). The inhibition activity was calculated by the equation: Inhibition $(\%)=[1-(A$ sample $/ A$ control $)] \times$ $100 \%$ [21]. Acarbose was also assayed as a positive reference. Concentrations of extracts resulting in 50\% inhibition of enzyme activity ( $\mathrm{IC}_{50}$ values) were determined graphically. Different propolis extracts were compared on the basis of their $\mathrm{IC}_{50}$ values estimated from the dose response curves.

2.6. Inhibitory Activity Assay for Rat Intestinal Sucrase. Rat intestinal sucrase inhibitory effects of propolis extracts were assayed according to a procedure described previously [22] with slight modifications. Briefly, $100 \mathrm{mg}$ rat intestinal acetone powder was homogenized in $15 \mathrm{~mL} 0.9 \% \mathrm{NaCl}$ solution $(\mathrm{w} / \mathrm{v})$. After centrifugation at $12,000 \mathrm{~g}$ for $40 \mathrm{~min}$, the supernatant was stored at $4^{\circ} \mathrm{C}$ as enzyme solution. $0.8 \mathrm{~mL}$ $56 \mathrm{mmol} / \mathrm{L}$ sucrose and $0.75 \mathrm{~mL} \mathrm{0.1} \mathrm{M} \mathrm{PIPES} \mathrm{buffer} \mathrm{(} \mathrm{pH} 7.0$ ) were premixed with $0.1 \mathrm{~mL}$ propolis extracts of various concentrations $(2 \mu \mathrm{g} / \mathrm{mL}-200 \mu \mathrm{g} / \mathrm{mL})$. After preincubating for $5 \mathrm{~min}$ at $37^{\circ} \mathrm{C}, 0.7 \mathrm{~mL}$ of the enzyme solution was added and the reaction was carried out at $37^{\circ} \mathrm{C}$ for $30 \mathrm{~min}$. The reaction was terminated by adding $0.75 \mathrm{~mL}$ of $2 \mathrm{~mol} / \mathrm{L}$ Tris- $\mathrm{HCl}$ buffer ( $\mathrm{pH}$ 6.9). For the blank, $0.1 \mathrm{~mL}$ DMSO was used in place of propolis extract. The concentration of glucose released from the reaction mixtures was determined colorimetrically using Glucose-Trinder 100 [23] and the absorbance measured at $505 \mathrm{~nm}$ after incubation at $37^{\circ} \mathrm{C}$ for $20 \mathrm{~min}$. The inhibition activity was calculated by the equation: Inhibition $(\%)=[1-$ (A sample/A control) $] \times 100 \%$. Acarbose was also assayed as a positive reference.

2.7. Inhibitory Activity Assay for Rat Intestinal Maltase. Rat intestinal maltase inhibitory effect of propolis extracts was assayed according to a procedure described previously [24]. The assay for rat intestinal maltase inhibitory activity was carried out in a similar manner as the rat intestinal sucrase inhibitory activity, except that $10 \mathrm{mM}$ maltose in $0.1 \mathrm{M}$ PIPES buffer ( $\mathrm{pH}$ 7.0) was used as a substrate. Acarbose was also assayed as a positive reference.

2.8. Inhibition Kinetics on Alpha-Glucosidase Activity. Inhibition model of different extracts of propolis on baker's yeast $\alpha$-glucosidase was tested according to procedure described previously [4] with minor modifications. Alpha-glucosidase activity was measured with increasing concentrations of PNP-glucoside $(0.4-6.0 \mathrm{mM})$ in the absence or presence of propolis extracts at various concentrations $(0.1-2.0 \mathrm{mg} / \mathrm{mL})$. The reaction was initiated by addition of enzyme and the reaction measured at $415 \mathrm{~nm}$ at 30-second interval for $15 \mathrm{~min}$. The enzyme assay data containing various concentration of PNP-glucoside and propolis extracts were used to construct the Lineweaver-Burk plots to determinate inhibition model, $V_{\max }$ and $\mathrm{Km}$ values.

2.9. Inhibition Constant Analysis. The inhibition constant of $\mathrm{p}$ ropolis on alpha-glucosidase was calculated by $\mathrm{Ki}=[I] /(\alpha-1)$,
TABLE 1: Total phenolic and flavonoid contents of various ethanol extracts of propolis.

\begin{tabular}{lcc}
\hline $\begin{array}{l}\text { Aqueous ethanol } \\
\text { extracts of propolis } \\
\text { (EEP) }\end{array}$ & $\begin{array}{c}\text { Total phenolic } \\
\text { contents } \\
\text { (mg GAE/g extracts) }\end{array}$ & $\begin{array}{c}\text { Total flavonoid } \\
\text { contents } \\
\text { (mg CE/g extracts) }\end{array}$ \\
\hline $\begin{array}{l}\text { Water extracts of } \\
\text { propolis (WEP) }\end{array}$ & $369.31 \pm 26.87^{\mathrm{ab}}$ & $352.32 \pm 0.67^{\mathrm{a}}$ \\
$\begin{array}{l}\text { 25\% ethanol } \\
\text { extracts of propolis } \\
\text { (25\% EEP) }\end{array}$ & $386.49 \pm 17.36^{\mathrm{a}}$ & $504.18 \pm 32.10^{\mathrm{b}}$ \\
$\begin{array}{l}50 \% \text { ethanol } \\
\text { extracts of propolis } \\
\begin{array}{l}\text { (50\% EEP) } \\
75 \% \text { ethanol }\end{array}\end{array}$ & $355.71 \pm 31.35^{\mathrm{ab}}$ & $620.80 \pm 4.08^{\mathrm{c}}$ \\
$\begin{array}{l}\text { extracts of propolis } \\
(75 \% \text { EEP) }\end{array}$ & $341.05 \pm 14.89^{\mathrm{b}}$ & $697.36 \pm 6.15^{\mathrm{d}}$ \\
$\begin{array}{l}95 \% \text { ethanol } \\
\text { extracts of propolis } \\
\text { (95\% EEP) }\end{array}$ & $312.65 \pm 24.13^{\mathrm{cb}}$ & $637.84 \pm 8.13^{\mathrm{cd}}$ \\
$\begin{array}{l}100 \% \text { ethanol } \\
\text { extracts of propolis } \\
(100 \% \text { EEP) }\end{array}$ & $273.94 \pm 1.76^{\mathrm{d}}$ & $673.24 \pm 5.96^{\mathrm{d}}$ \\
\hline
\end{tabular}

Note: Water extracts of propolis were expressed as WEP. Extracts of propolis using $25 \%, 50 \%, 75 \%, 95 \%$, and $100 \%$ (in water, v/v) aqueous ethanol solvents were expressed as 25\% EEP, 50\% EEP, 75\% EEP, 95\% EEP, and $100 \%$ EEP, respectively. TPC was expressed as milligram of gallic acid equivalent per gram of propolis extracts (mg GAE/g extracts). TFC was expressed as milligram of rutin equivalent per gram of propolis extracts (mg RE/g extracts). Dates are mean \pm standard deviation $(n=3)$. Values in the same column followed by the same lower case letter are not significantly different by Duncan's multiple range test $(P<0.05)$.

where $[I]$ represents the concentration of inhibitor, and $\alpha$ is confirmed by $v=\left(V_{\max } / \alpha[S]\right) /(\mathrm{Km}+[S]) . V_{\max }$ and $\mathrm{Km}$ values were obtained from the above assay, and $[S]$ represents the concentration of substrate.

2.10. Statistical Analysis. Experimental results were expressed as mean \pm standard deviation (SD) of triplicate measurements. The data were subjected to one way analysis of variance (ANOVA). Significance differences at $P<0.05$ among treatment means were obtained using Duncan's multiple range test using SAS version 9.1 (SAS Institute Inc., Cary, NC, USA).

\section{Results and Discussion}

3.1. Total Phenolic and Flavonoid Contents of Aqueous Ethanol Extracts of Propolis. Phenolics are the predominant bioactive materials in propolis which have been reported to have multiple biological effects, including antidiabetes. Therefore, measurement of total phenolic contents (TPC) and total flavonoid contents (TFC) was inevitable. Total phenolic and flavonoid contents in various aqueous ethanol extracts of propolis are presented in Table 1. TPC ranged from 273.94 to $386.49 \mathrm{mgGAE} / \mathrm{g}$ extracts increasing in the following order: $25 \% \mathrm{EEP}>\mathrm{WEP}>50 \% \mathrm{EEP}>75 \% \mathrm{EEP}>95 \% \mathrm{EEP}$ $>100 \%$ EEP. TPC was not significantly different among WEP, 25\% EEP, and 50\% EEP. TFC ranged from 352.32 to 
$697.36 \mathrm{mg} \mathrm{CE} / \mathrm{g}$ extracts increasing in the following order: $75 \% \mathrm{EEP}>100 \% \mathrm{EEP}>95 \% \mathrm{EEP}>50 \% \mathrm{EEP}>25 \% \mathrm{EEP}>$ WEP. TFC was not significantly different among 100\% EEP, 95\% EEP, and 75\% EEP.

The total phenolic and flavonoid contents of propolis extracts varied with different concentrations of hydrous ethanol. A similar report shows that ethanol/water concentrations correlate with the amount and composition of phenolic compounds and flavonoids of propolis extracts [25]. Moreover, propolis from various areas of China was found to contain a wide variety of bioactive compounds, mainly phenolic acids and flavonoids [26]. In the current study, while ethanol concentrations in hydrous ethanol were less than $50 \%$ as extraction solvent, the TPC of these extracts were significantly higher than those containing higher ethanol concentrations $(P<0.05)$. These propolis extracts may mainly contain more hydrophilic phenolic compounds, cinnamic acid derivatives [27]. On the other hand, when ethanol concentrations were higher than $50 \%$, TFC of the extracts were significantly higher compared to those with lower ethanol concentrations $(P<0.05)$. These propolis extracts mainly contain a significant increase in the ratio of more hydrophobic flavonoid compounds, such as apigenin, kaempferol, and chrysin [26].

3.2. Inhibition of Aqueous Ethanol Extracts of Propolis against Alpha-Glucosidase. The $\alpha$-glucosidase inhibitory activity of various propolis extracts is shown in Table 2. The propolis extracts had ever been found to be reversibly bound to $\alpha$-glucosidase in our previous report. The effectiveness of enzymatic inhibition of the various extracts was determined by calculating $\mathrm{IC}_{50}$. The lower the value showed, the higher the enzymatic inhibition. $\mathrm{IC}_{50}$ values of propolis extracts ranged from 7.24 to $20.01 \mu \mathrm{g} / \mathrm{mL}$ against baker's yeast $\alpha$ glucosidase and from 32.34 to $53.12 \mu \mathrm{g} / \mathrm{mL}$ against rat intestinal sucrase. These values were significantly $(P<0.05)$ lower than $177.5 \mu \mathrm{g} / \mathrm{mL}$ and $538.3 \mu \mathrm{g} / \mathrm{mL}$ of acarbose, a positive reference, respectively. Thus, all propolis extracts possessed much stronger inhibitory effects on $\alpha$-glucosidase from baker's yeast and sucrase compared to acarbose. The 75\% EEP showed the highest inhibitory effect on $\alpha$-glucosidase from baker's yeast and sucrase, and $\mathrm{IC}_{50}$ values accounted for only $4 \%$ and $6 \%$ of that of acarbose, respectively. For rat intestinal maltase, WEP had the highest inhibitory activity among all extracts with $\mathrm{IC}_{50}$ value of $32.67 \mu \mathrm{g} / \mathrm{mL}$ that was significantly higher than that of acarbose of $22.5 \mu \mathrm{g} / \mathrm{mL}(P<0.05)$. All propolis extracts showed weak inhibitory effects on maltase in comparison to acarbose.

Many plant extracts from food and Chinese traditional medicine have been reported to have antidiabetic activity [5]. These antidiabetic phytochemicals are probably comprising phenolic compounds, such as flavonoids and phenolic acids [28]. Propolis extracts contain phenolic compounds which are classified into two major categories, phenolic acids and flavonoids. As shown in Table 1, TPC and TFC of various ethanol extracts of propolis were different. Similarly, the inhibitory effects of various propolis extracts on alphaglucosidases were also different (Table 2). The 75\% EEP possessed the highest flavonoid contents and the strongest
TABLE 2: Inhibition of propolis extracts against yeast and rat intestinal alpha-glucosidase.

\begin{tabular}{|c|c|c|c|}
\hline \multirow{2}{*}{$\begin{array}{l}\text { Aqueous } \\
\text { ethanol extracts } \\
\text { of propolis } \\
\text { (EEP) }\end{array}$} & \multicolumn{3}{|c|}{$\mathrm{IC}_{50}(\mu \mathrm{g} / \mathrm{mL})$} \\
\hline & $\begin{array}{c}\text { Baker's yeast } \\
\text { alpha- } \\
\text { glucosidase }\end{array}$ & $\begin{array}{l}\text { Rat intestinal } \\
\text { sucrase }\end{array}$ & $\begin{array}{c}\text { Rat intestinal } \\
\text { maltase }\end{array}$ \\
\hline WEP & $16.0 \pm 1.38^{b c}$ & $37.91 \pm 0.52^{\mathrm{ab}}$ & $32.67 \pm 0.24^{\mathrm{e}}$ \\
\hline 25\% EEP & $11.32 \pm 2.23^{\mathrm{ab}}$ & $40.25 \pm 0.97^{\mathrm{ab}}$ & $44.80 \pm 0.25^{\mathrm{d}}$ \\
\hline $50 \%$ EEP & $12.90 \pm 1.14^{\mathrm{b}}$ & $53.12 \pm 0.95^{\mathrm{b}}$ & $100.60 \pm 2.95^{b}$ \\
\hline $75 \%$ EEP & $7.24 \pm 1.16^{\mathrm{a}}$ & $32.34 \pm 0.61^{\mathrm{a}}$ & $71.82 \pm 2.95^{c}$ \\
\hline 95\% EEP & $16.26 \pm 0.43^{b c}$ & $32.91 \pm 0.54^{\mathrm{a}}$ & $102.76 \pm 1.47^{\mathrm{b}}$ \\
\hline $100 \%$ EEP & $20.01 \pm 1.54^{\mathrm{c}}$ & $38.06 \pm 0.56^{\mathrm{ab}}$ & $131.12 \pm 1.83^{\mathrm{a}}$ \\
\hline Acarbose & $177.47 \pm 6.28^{\mathrm{d}}$ & $538.30 \pm 26.69^{\mathrm{c}}$ & $22.46 \pm 0.86^{\mathrm{f}}$ \\
\hline
\end{tabular}

Note: Water extracts of propolis were expressed as WEP. Extracts of propolis using $25 \%, 50 \%, 75 \%, 95 \%$, and $100 \%$ (in water, v/v) aqueous ethanol solvents were expressed as 25\% EEP, 50\% EEP, 75\% EEP, 95\% EEP, and $100 \%$ EEP, respectively. Dates are mean \pm standard deviation $(n=3)$. Values in the same column followed by the same lower case letter are not significantly different by Duncan's multiple range test $(P<0.05)$. Inhibition of propolis extracts against yeast and rat intestinal alpha-glucosidase were both expressed as $\mathrm{IC}_{50}$ (concentration of total phenolics able to scavenger $50 \%$ of alpha-glucosidase activity).

inhibitory effect on $\alpha$-glucosidases from baker's yeast and rat intestinal sucrase among all extracts. Wang et al. [29] also reported that some flavonoids have the higher inhibitory effect on rat sucrase than that of rat maltase. Moreover, the study revealed WEP and 25\% EEP had higher TPC and stronger inhibitory effects on rat intestinal maltase among all extracts. Some phenolics such as chebulanin, chebulagic acid, and chebulinic acid were reported to have the same potential against rat intestinal maltase [30]. Kamiyama et al. [31] similarly found that some catechin derivatives had better inhibitory activity against rat intestinal maltase than rat intestinal sucrase. Therefore, it seems to assume that extracts with higher TFC could have better inhibition against rat intestinal sucrase; similarly extracts with higher TPC could possess better inhibition against rat intestinal maltase.

\subsection{Inhibitory Kinetics of Aqueous Ethanol Extracts of Propolis} against Baker's Yeast Alpha-Glucosidase. Yeast $\alpha$-glucosidase is readily available in a pure form and has been widely used for antidiabetic nutraceutical and medicinal investigations as a model for screening potential inhibitors and studying inhibitory mechanism [5]. To find the inhibition mechanism of aqueous ethanol extracts of propolis, inhibitory kinetics against yeast $\alpha$-glucosidase was analyzed by LineweaverBurk plots using data derived from enzyme assay containing different concentrations of PNP-glucoside in the absence or presence of different concentration of inhibitor.

As can be seen in Table 3, various aqueous ethanol extracts of propolis had different inhibition modes. Doublereciprocal plots of enzyme kinetics demonstrated that the inhibition of WEP and 25\% EEP was competitive inhibition mode (Figures 1(a) and 1(b)), and the Ki values were $10.43 \mu \mathrm{g} / \mathrm{mL}$ and $9.85 \mu \mathrm{g} / \mathrm{mL}$ (Table 3). Plots also indicated that the type of 50\% EEP, 95\% EEP, and 100\% EEP was 


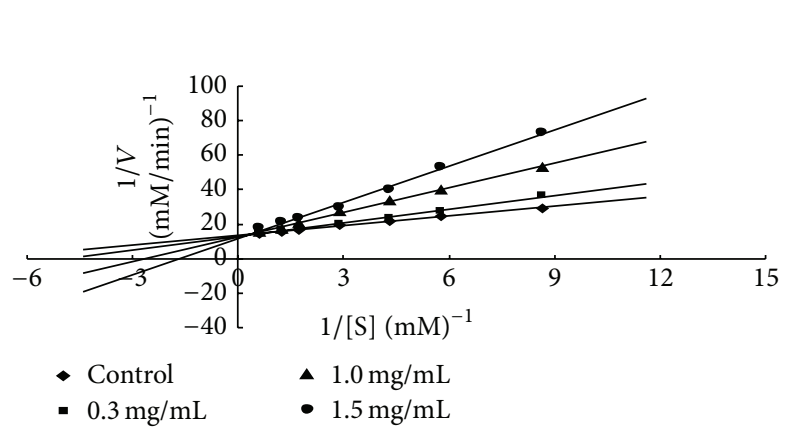

(a)

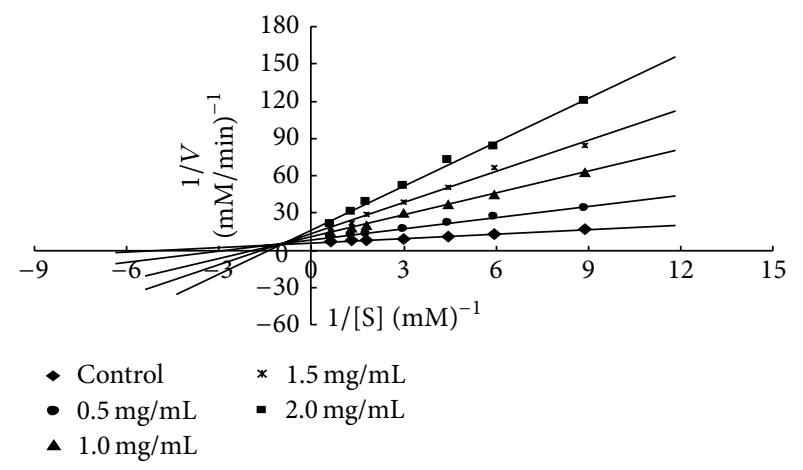

(c)

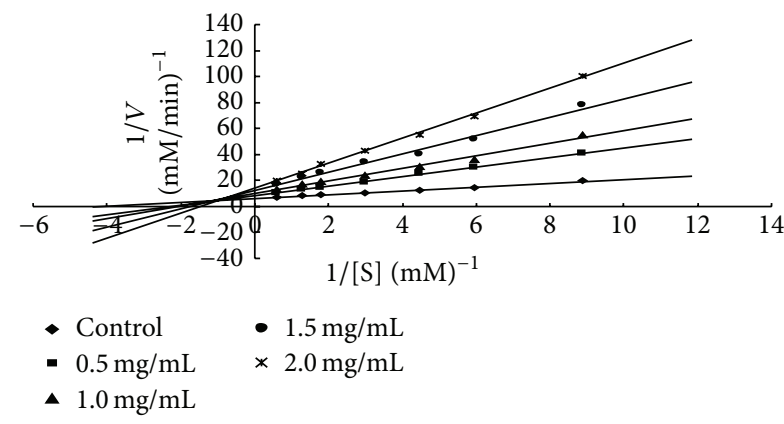

(e)

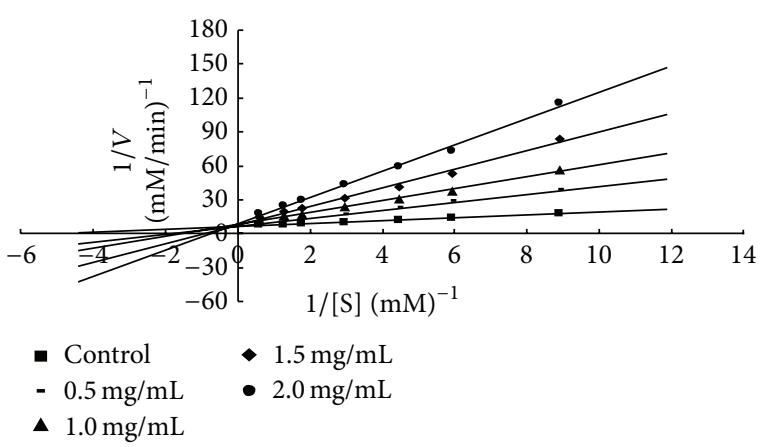

(b)

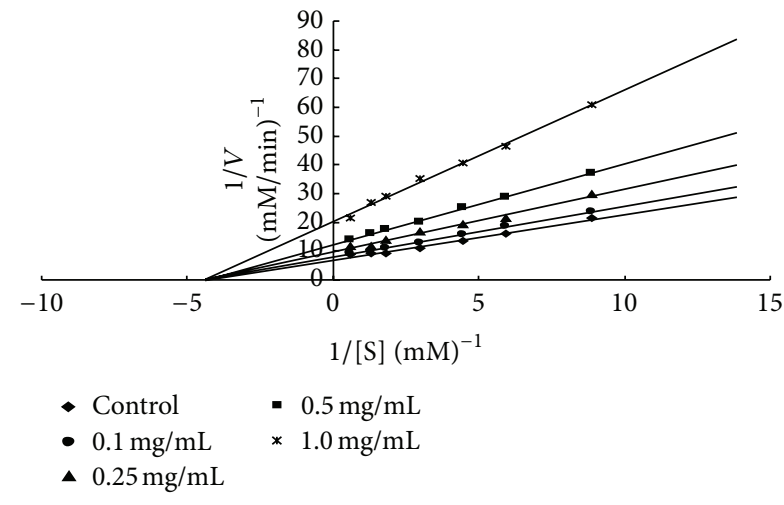

(d)

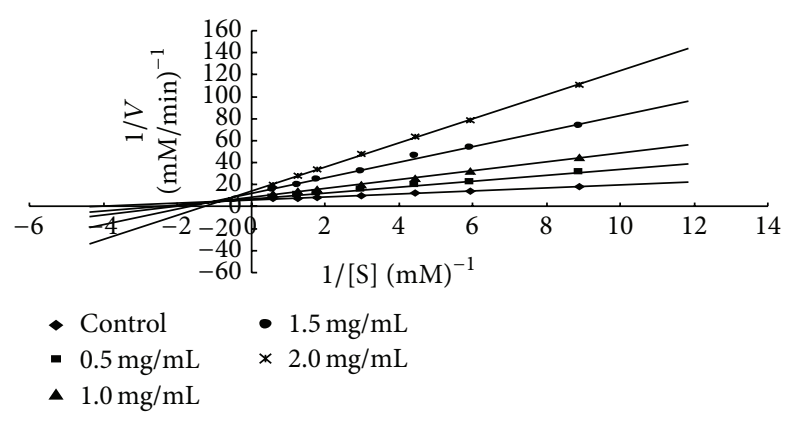

(f)

FIGURE 1: Lineweaver-Burk plots of inhibition kinetics of yeast alpha-glucosidase inhibitory effects by WEP (a), 25\% EEP (b), 50\% EEP (c), $75 \%$ EEP (d), 95\% EEP (e), and 100\% EEP (f). Water extracts of propolis were expressed as WEP. Extracts of propolis using 25\%, 50\%, 75\%, $95 \%$, and $100 \%$ (in water, v/v) aqueous ethanol solvents were expressed as 25\% EEP, 50\% EEP, 75\% EEP, 95\% EEP, and 100\% EEP, respectively.

mixed inhibition mode (Figures 1(c), 1(e), and 1(f)), and the Ki values were $9.92 \mu \mathrm{g} / \mathrm{mL}, 9.65 \mu \mathrm{g} / \mathrm{mL}$, and $10.89 \mu \mathrm{g} / \mathrm{mL}$, respectively (Table 3). Moreover, inhibitory mode of $75 \%$ EEP was noncompetitive inhibition (Figure $1(\mathrm{~d})$ ), and the Ki value was $15.18 \mu \mathrm{g} / \mathrm{mL}$, a value significantly higher than those of other extracts $(P<0.05)$.

Phenolic compounds are able to inhibit the activities of carbohydrate-hydrolysing enzymes due to their ability to bind with proteins [32]. As can be seen, different aqueous ethanol extracts of propolis were revealed to have different inhibition modes against $\alpha$-glucosidase. Probably that is because phenolic compounds in different EEP have different bound modes with $\alpha$-glucosidase. The inhibition of WEP and $25 \%$ EEP was a competitive mode characterized by the fact that the substrate and inhibitor compete for the same binding site in the enzyme, the so-called active site or substratebinding site. It indicated that phenolic compounds in WEP and $25 \%$ EEP can bind to the active site of $\alpha$-glucosidase. The inhibition of $75 \%$ EEP was a noncompetitive mode in that inhibitor is not binding to the active site on $\alpha$-glucosidase. Inhibition mode was a mixed inhibition for 50\% EEP, 95\% EEP, and $100 \%$ EEP. For the noncompetitive and mixed inhibition mode, the binding of inhibitor can influence the binding of substrate by changing the conformation of the enzyme. Different inhibition modes shown by various EEP were likely due to the different bioactive compounds in the extracts. 75\% EEP was found to contain the highest TFC among EEP and exhibit noncompetitive inhibition. TFC of 
TABLE 3: Inhibitory kinetics and Ki values of various propolis extracts against baker's yeast alpha-glucosidase.

\begin{tabular}{lcc}
\hline $\begin{array}{l}\text { Aqueous ethanol } \\
\text { extracts of propolis } \\
(\mathrm{EEP})\end{array}$ & Kinetic mode & $\mathrm{Ki}(\mu \mathrm{g} / \mathrm{mL})$ \\
\hline WEP & Competitive inhibition & $10.43 \pm 1.41^{\mathrm{b}}$ \\
$25 \% \mathrm{EEP}$ & Competitive inhibition & $9.85 \pm 2.48^{\mathrm{b}}$ \\
$50 \% \mathrm{EEP}$ & Mixed inhibition & $9.92 \pm 0.43^{\mathrm{b}}$ \\
$75 \% \mathrm{EEP}$ & Noncompetitive inhibition & $15.18 \pm 0.58^{\mathrm{a}}$ \\
$95 \% \mathrm{EEP}$ & Mixed inhibition & $9.65 \pm 1.54^{\mathrm{b}}$ \\
$100 \% \mathrm{EEP}$ & Mixed inhibition & $10.89 \pm 2.84^{\mathrm{b}}$ \\
\hline
\end{tabular}

Note: Water extracts of propolis were expressed as WEP. Extracts of propolis using $25 \%, 50 \%, 75 \%, 95 \%$, and $100 \%$ (in water, $\mathrm{v} / \mathrm{v}$ ) aqueous ethanol solvents were expressed as 25\% EEP, 50\% EEP, 75\% EEP, 95\% EEP, and 100\% EEP, respectively. The inhibition constant of propolis on alpha-glucosidase was expressed as Ki. Dates are mean \pm standard deviation $(n=3)$. Values in the same column followed by the same lower case letter are not significantly different by Duncan's multiple range test $(P<0.05)$.

95\% EEP and 100\% EEP were lower but not significantly different than 75\% EEP and showed mixed inhibition. A similar trend was observed that many flavonoids exhibited mixed or noncompetitive type of inhibition [28, 33]. WEP and 25\% EEP contained the higher TPC and exhibited a competitive inhibition mode. The ethanol extract of G. montanum rich in phenolic composition also showed competitive inhibition against yeast $\alpha$-glucosidase [34]. It seems to assume that inhibition of aqueous ethanol extracts of propolis with the higher TPC is likely a competitive mode while those with higher TFC tend to have a noncompetitive or mixed mode.

All aqueous ethanol extracts of propolis showed stronger inhibition against the yeast $\alpha$-glucosidase compared to acarbose, especially for those extracts using the higher concentration of ethanol as the solvent. It is probably that the ability to bind to wide regions of enzyme other than the active site enables these propolis extracts as noncompetitive or mixed inhibitors a broader specificity of inhibition, compared with acarbose, a competitive inhibitor. Another advantage of aqueous ethanol extracts of propolis over acarbose is that these propolis extracts, noncompetitive or mixed inhibitors, may not be affected by the higher concentration of the substrate in contrast to acarbose which is a competitive inhibitor. It is reported that, with higher carbohydrate food intake, higher concentrations of acarbose as a competitive inhibitor would be needed to show the same effect. For mixed inhibition, the inhibitor would be still effective at lower concentrations [6].

\section{Conclusion}

In the present study, all aqueous ethanol extracts of propolis show stronger inhibitory effects on yeast $\alpha$-glucosidase and rat intestinal sucrose than that of acarbose as a positive reference. Our findings seem to prove that the controlling glycemia of propolis may be related to the inhibitory activities against $\alpha$-glucosidase. Thus, aqueous ethanol extracts of propolis may be used as nutraceuticals for the regulation of postprandial hyperglycemia. For further study, the fractions from propolis having inhibitory activity against $\alpha$ glucosidase are being purified and their chemical structures are being characterized.

\section{Conflict of Interests}

The authors declare that there is no conflict of interests.

\section{Acknowledgments}

This research was supported by a grant project of 12th Five Years' National Science and Technology Support Programme (2011BAD33B04) from the Ministry of Science \& Technology of China.

\section{References}

[1] A. Andrade-Cetto, J. Becerra-Jiménez, and R. CárdenasVázquez, "Alfa-glucosidase-inhibiting activity of some Mexican plants used in the treatment of type 2 diabetes," Journal of Ethnopharmacology, vol. 116, no. 1, pp. 27-32, 2008.

[2] Q. H. Dai and Z. D. Wang, "Current survey of Chinese diabetes," in Guide of China Medicine, vol. 13, pp. 210-212, 2011.

[3] N. Ahmed, "Advanced glycation endproducts-role in pathology of diabetic complications," Diabetes Research and Clinical Practice, vol. 67, no. 1, pp. 3-21, 2005.

[4] L. J. Shai, P. Masoko, M. P. Mokgotho et al., "Yeast alpha glucosidase inhibitory and antioxidant activities of six medicinal plants collected in Phalaborwa, South Africa," South African Journal of Botany, vol. 76, no. 3, pp. 465-470, 2010.

[5] F. Ye, Z. Shen, and M. Xie, "Alpha-glucosidase inhibition from a Chinese medical herb (Ramulus mori) in normal and diabetic rats and mice," Phytomedicine, vol. 9, no. 2, pp. 161-166, 2002.

[6] V. Ghadyale, S. Takalikar, V. Haldavnekar, and A. Arvindekar, "Effective control of postprandial glucose level through inhibition of intestinal alpha glucosidase by Cymbopogon martinii (Roxb.)," Evidence-Based Complementary and Alternative Medicine, vol. 2012, Article ID 372909, 6 pages, 2012.

[7] T. Matsui, T. Ueda, T. Oki, K. Sugita, N. Terahara, and K. Matsumoto, " $\alpha$-glucosidase inhibitory action of natural acylated anthocyanins. 1. Survey of natural pigments with potent inhibitory activity," Journal of Agricultural and Food Chemistry, vol. 49, no. 4, pp. 1948-1951, 2001.

[8] A. Murai, K. Iwamura, M. Takada, K. Ogawa, T. Usui, and J.-I. Okumura, "Control of postprandial hyperglycaemia by galactosyl maltobionolactone and its novel anti-amylase effect in mice," Life Sciences, vol. 71, no. 12, pp. 1405-1415, 2002.

[9] J. Shinde, T. Taldone, M. Barletta et al., " $\alpha$-Glucosidase inhibitory activity of Syzygium cumini (Linn.) Skeels seed kernel in vitro and in Goto-Kakizaki (GK) rats," Carbohydrate Research, vol. 343, no. 7, pp. 1278-1281, 2008.

[10] A. Andrade-Cetto, J. Becerra-Jiménez, and R. CárdenasVázquez, "Alfa-glucosidase-inhibiting activity of some Mexican plants used in the treatment of type 2 diabetes," Journal of Ethnopharmacology, vol. 116, no. 1, pp. 27-32, 2008.

[11] A. H. Banskota, Y. Tezuka, and S. Kadota, "Recent progress in pharmacological research of propolis," Phytotherapy Research, vol. 15, no. 7, pp. 561-571, 2001.

[12] V. Bankova, "Recent trends and important developments in propolis research," Evidence-Based Complementary and Alternative Medicine, vol. 2, no. 1, pp. 29-32, 2005. 
[13] H. U. Fuliang, H. R. Hepburn, H. Xuan, M. Chen, S. Daya, and S. E. Radloff, "Effects of propolis on blood glucose, blood lipid and free radicals in rats with diabetes mellitus," Pharmacological Research, vol. 51, no. 2, pp. 147-152, 2005.

[14] W. Y. Yan, M. Yang, X. Y. Yang et al., "Effects of the propolis extracted by two methods on the blood glucose in the rats suffering from type 2 diabetes," Journal of Fojian Agriculture and Forestry University (Natural Science Edition), vol. 37, no. 2, pp. 194-195, 2008.

[15] M. C. Búfalo, D. P. Barreiro, D. R. S. Sartori, and J. M. Sforcin, "Absence of propolis effect on plasma glycaemic control and lipid metabolism in a diabetic rat model," Journal of Apiproduct and Apimedical Science, vol. 1, no. 2, pp. 51-55, 2009.

[16] State Administration of Traditional Chinese Medicine, Chinese Herbal Medicine, Shanghai Science and Technology Press, Shanghai, China, 1999.

[17] State Pharmacopoeia Commission, Chinese Pharmacopoeia, Chemical Industry Press, Beijing, China, 2005.

[18] W. Huang, A. Xue, H. Niu, Z. Jia, and J. Wang, "Optimised ultrasonic-assisted extraction of flavonoids from Folium eucommiae and evaluation of antioxidant activity in multi-test systems in vitro," Food Chemistry, vol. 114, no. 3, pp. 1147-1154, 2009.

[19] S. Kumazawa, K. Hayashi, K. Kajiya, T. Ishii, T. Hamasaka, and T. Nakayama, "Studies of the constituents of Uruguayan propolis," Journal of Agricultural and Food Chemistry, vol. 50, no. 17, pp. 4777-4782, 2002.

[20] M. Kaijv, L. Sheng, and C. Chao, "Antioxidation of flavonoids of green rhizome," Food Science, vol. 27, pp. 110-115, 2006.

[21] Y.-M. Kim, Y.-K. Jeong, M.-H. Wang, W.-Y. Lee, and H.-I. Rhee, "Inhibitory effect of pine extract on $\alpha$-glucosidase activity and postprandial hyperglycemia," Nutrition, vol. 21, no. 6, pp. 756761, 2005.

[22] T. Nishioka, J. Kawabata, and Y. Aoyama, "Baicalein, an $\alpha$ glucosidase inhibitor from Scutellaria baicalensis," Journal of Natural Products, vol. 61, no. 11, pp. 1413-1415, 1998.

[23] J.-K. Hwang, T.-W. Kong, N.-I. Baek, and Y.-R. Pyun, “ $\alpha$ Glycosidase inhibitory activity of hexagalloylglucose from the galls of Quercus infectoria," Planta Medica, vol. 66, no. 3, pp. 273-274, 2000.

[24] M. Toda, J. Kawabata, and T. Kasai, " $\alpha$-Glucosidase inhibitors from Clove (Syzgium aromaticum)," Bioscience, Biotechnology and Biochemistry, vol. 64, no. 2, pp. 294-298, 2000.

[25] S. M. Cottica, A. C. H. F. Sawaya, M. N. Eberlin, S. L. Franco, L. M. Zeoula, and J. V. Visentainer, "Antioxidant activity and composition of propolis obtained by different methods of extraction," Journal of the Brazilian Chemical Society, vol. 22, no. 5, pp. 929-935, 2011.

[26] J. H. Zhou, Y. Li, J. Zhao, X. F. Xue, L. M. Wu, and F. Chen, "Geographical traceability of propolis by high-performance liquid-chromatography fingerprints," Food Chemistry, vol. 108, no. 2, pp. 749-759, 2008.

[27] Y. Nakajima, M. Shimazawa, S. Mishima, and H. Hara, "Water extract of propolis and its main constituents, caffeoylquinic acid derivatives, exert neuroprotective effects via antioxidant actions," Life Sciences, vol. 80, no. 4, pp. 370-377, 2007.

[28] K. Tadera, Y. Minami, K. Takamatsu, and T. Matsuoka, "Inhibition of $\alpha$-glucosidase and $\alpha$-amylase by flavonoids," Journal of Nutritional Science and Vitaminology, vol. 52, no. 2, pp. 149-153, 2006.

[29] H. Wang, Y.-J. Du, and H.-C. Song, " $\alpha$-Glucosidase and $\alpha$ amylase inhibitory activities of guava leaves," Food Chemistry, vol. 123, no. 1, pp. 6-13, 2010.
[30] S. Kumar, S. Narwal, V. Kumar, and O. Prakash, " $\alpha$-glucosidase inhibitors from plants: a natural approach to treat diabetes," Pharmacognosy Reviews, vol. 5, no. 9, pp. 19-29, 2011.

[31] O. Kamiyama, F. Sanae, K. Ikeda et al., "In vitro inhibition of $\alpha$ glucosidases and glycogen phosphorylase by catechin gallates in green tea," Food Chemistry, vol. 122, no. 4, pp. 1061-1066, 2010.

[32] S. Shobana, Y. N. Sreerama, and N. G. Malleshi, "Composition and enzyme inhibitory properties of finger millet (Eleusine coracana L.) seed coat phenolics: mode of inhibition of $\alpha$ glucosidase and pancreatic amylase," Food Chemistry, vol. 115, no. 4, pp. 1268-1273, 2009.

[33] H. Xu, "Inhibition kinetics of flavonoids on yeast $\alpha$-glucosidase merged with docking simulations," Protein and Peptide Letters, vol. 17, no. 10, pp. 1270-1279, 2010.

[34] K. M. Ramkumar, B. Thayumanavan, T. Palvannan, and P. Rajaguru, "Inhibitory effect of Gymnema montanum leaves on $\alpha$-glucosidase activity and $\alpha$-amylase activity and their relationship withpolyphenolic content," Medicinal Chemistry Research, vol. 19, no. 8, pp. 948-961, 2010. 


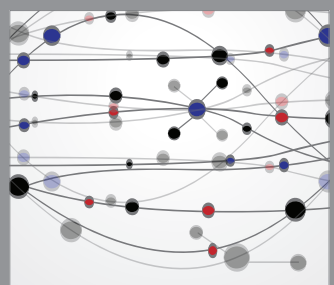

The Scientific World Journal
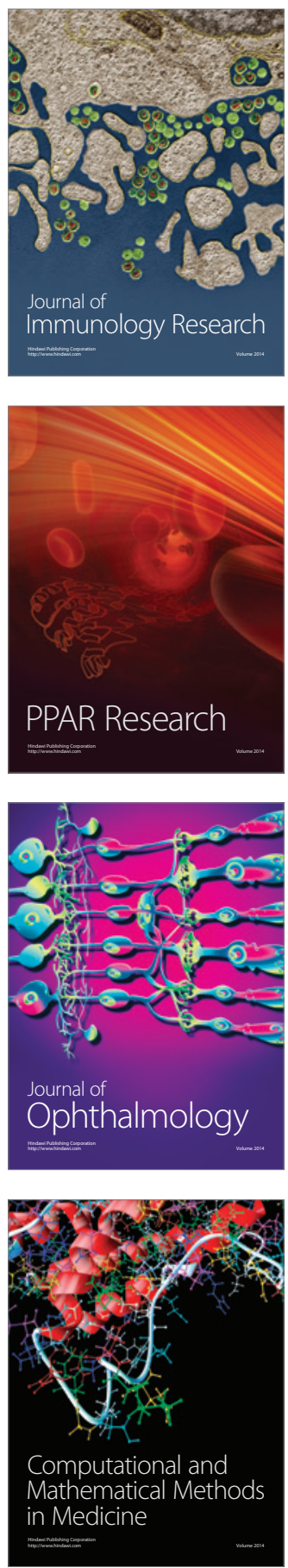

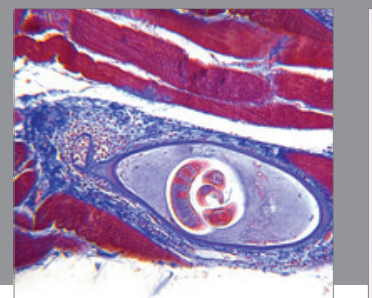

Gastroenterology

Research and Practice
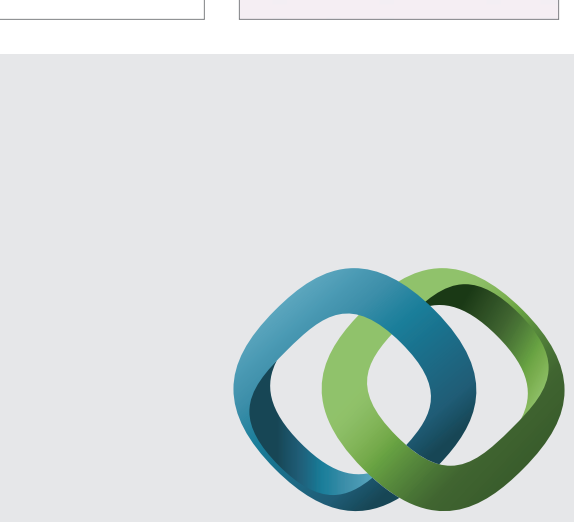

\section{Hindawi}

Submit your manuscripts at

http://www.hindawi.com
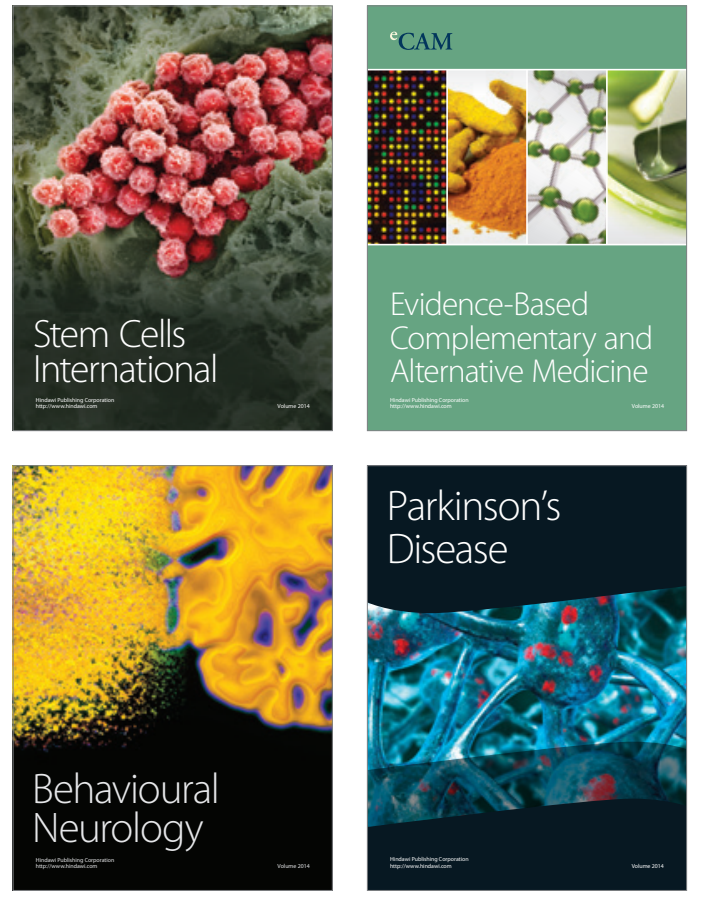
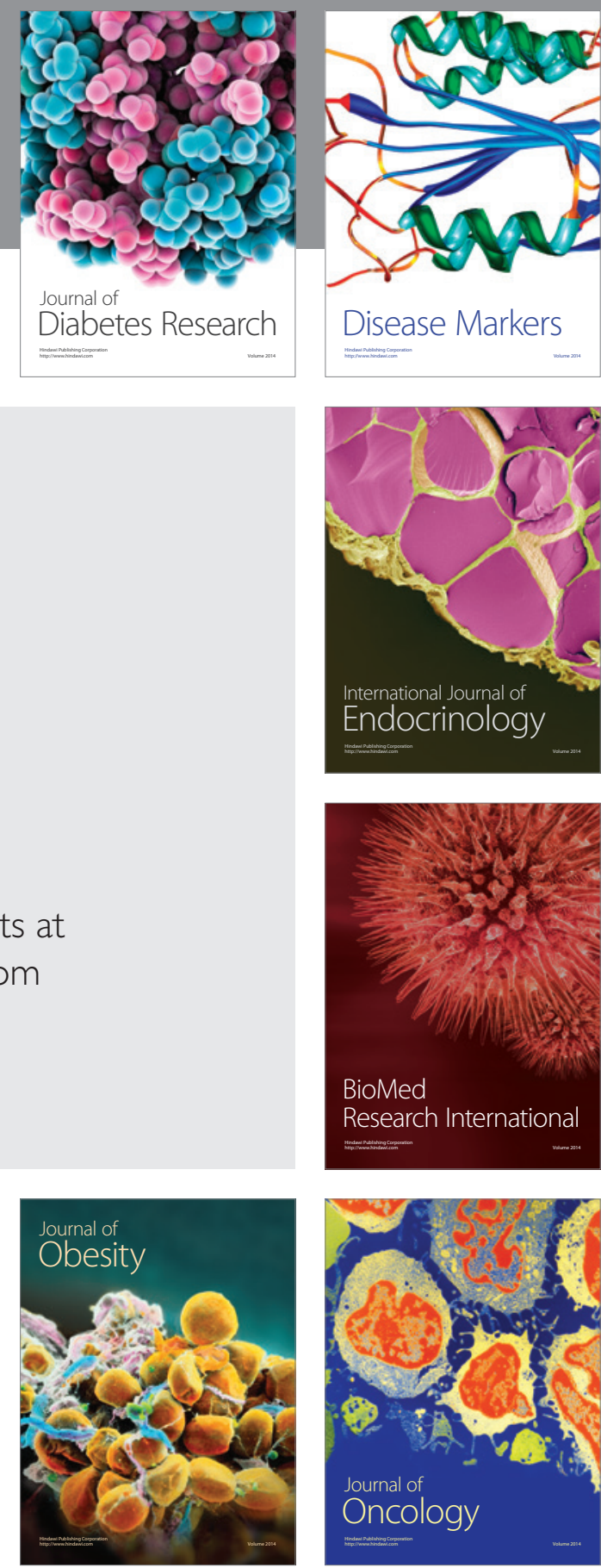

Disease Markers
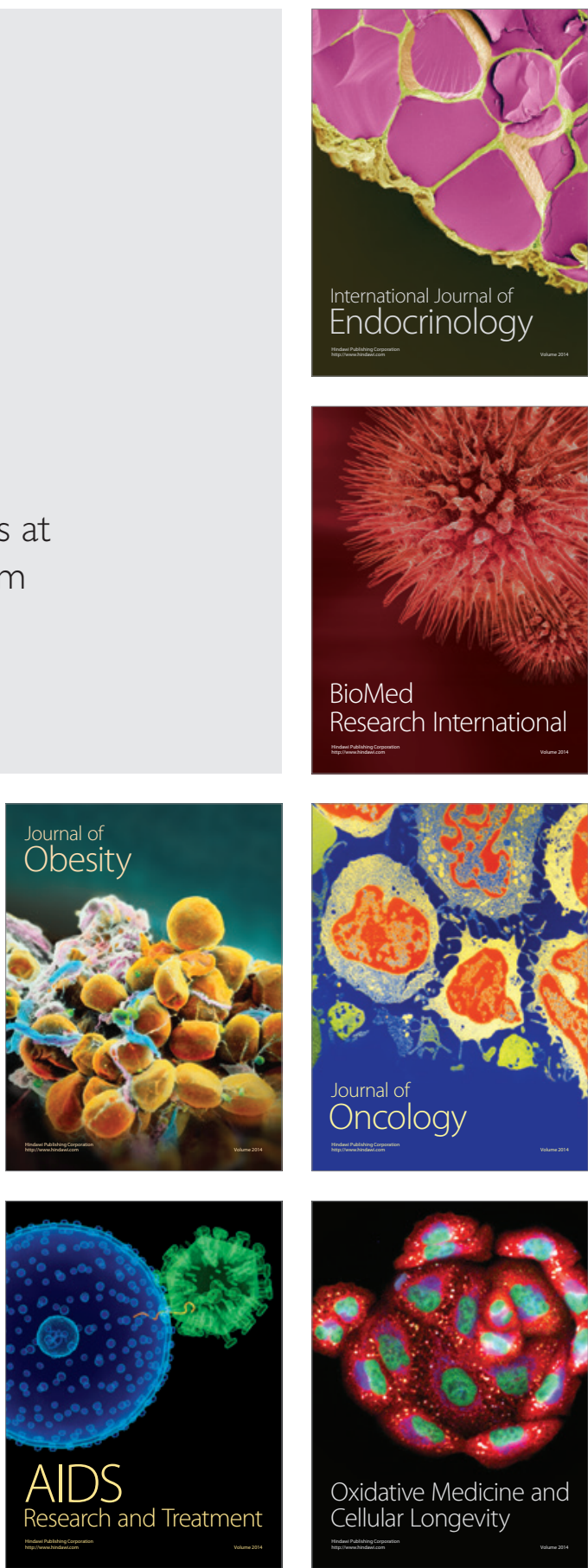